\title{
The dynamics identification of asynchronous electric drives via frequency response
}

Vladimir L. Kodkin, Aleksandr S. Anikin, Aleksandr A. Baldenkov

Department of Theoretical Fundamentals of Electrical Engineering, South Ural State University (NRU), Russia

\begin{tabular}{|c|c|}
\hline Article Info & ABSTRACT \\
\hline Article history: & \multirow{10}{*}{$\begin{array}{l}\text { The article substantiates the necessity of identifying the dynamics of } \\
\text { asynchronous electric drives with frequency control. It is proposed to use } \\
\text { nonlinear transfer functions and the formula of a family of frequency } \\
\text { responses of an electric drive, depending on the frequency of the stator } \\
\text { voltage and slip. Experiments and simulations confirming theoretical } \\
\text { conclusions are presented. The frequency responses of the drive of the stand } \\
\text { calculated by the proposed method allowed to explain those problems of } \\
\text { frequency control that were not explained by traditional methods - analytical, } \\
\text { vector diagrams, substitution schemes, etc. This same technique allowed us } \\
\text { to formulate a structural correction of the asynchronous electric drives. In } \\
\text { contrast to the previously published research materials of asynchronous } \\
\text { electric drives, a detailed qualitative analysis of the obtained nonlinear } \\
\text { frequency responses and the interrelation of these characteristics with } \\
\text { experimental results is shown for the first time in the article. }\end{array}$} \\
\hline Received Aug 23, 2018 & \\
\hline & \\
\hline Accepted Nov 4, 2018 & \\
\hline Keywords: & \\
\hline Asynchronous electric drive & \\
\hline Dynamics of the electric drive & \\
\hline Frequency control & \\
\hline Frequency response & \\
\hline & \\
\hline
\end{tabular}

Copyright (C) 2019 Institute of Advanced Engineering and Science. All rights reserved.

\section{Corresponding Author:}

Aleksandr S. Anikin,

Department of Theoretical Fundamentals of Electrical Engineering,

South Ural State University,

76, Lenin prospekt, Chelyabinsk, Russia. 454080.

Email: anikinas@susu.ru

\section{INTRODUCTION}

In industrial mechanisms the electric drives of the actuating elements play a very important role. In the final analysis their accuracy depends on the quality of the execution of technological operations, on their ability to "parry" disturbances-changes in air temperature, "failures" and "throws" of the power voltage, wear of mechanical parts, and, what is especially important, the quality of technical complexes in general, and their competitiveness [1]-[3].

In recent years, in the high-tech executive mechanisms most often used permanent magnet synchronous motors. Their adjusting capabilities are commensurate with DC drives, and the absence of collectors significantly increases their service life. However, these engines can provide the required accuracy and robustness (roughness) to external influences, only with sufficiently complex regulators, with numerous sensors - engine speed, acceleration, motor currents, power voltage, etc. [4]-[10].

Significantly better properties of "robustness" are AC drives with asynchronous and synchronous motors, the latter, as a rule, differ from the valve motors only in the control method. But it is the control problems that are the reason why AC drives are still rarely used in complex technological mechanisms.

\section{PROBLEM DEFINITION}

One of the problems that greatly affects the formation of provisions for the control of AC drives is the absence (or almost absence) of an engineering apparatus for estimating the dynamics of AC drives, in particular asynchronous electric drives. Assumptions, which are usually given in the works, in particular, in 
the monograph of A.A. Usoltsev [11], simplify the structure so much that they do not reflect the features and problems of the dynamics of these drives, which one has to face in practice [12], [13].

The nonlinearity of a drive with an asynchronous motor is well known; it is stored in all known control methods - scalar, vector, DTC (Direct Torque Control). This nonlinearity is manifested in the experiments described in [14]-[19]. The electric drive was subsequently accelerated to speeds corresponding to the frequencies of the supply voltage of $10-20-30-40-50 \mathrm{~Hz}$, at each speed of rotation a load was drawn is shown in Figures 1 and 2.

Both the modeling of the processes is shown in Figures 1 and 2, and the experimental studies is shown in Figure 3. Show that the processes differ qualitatively at different drive speeds. Therefore, they must be described by different frequency responses. The task to be solved first of all is the formation of the frequency responses of an asynchronous drive, for each particular mode.

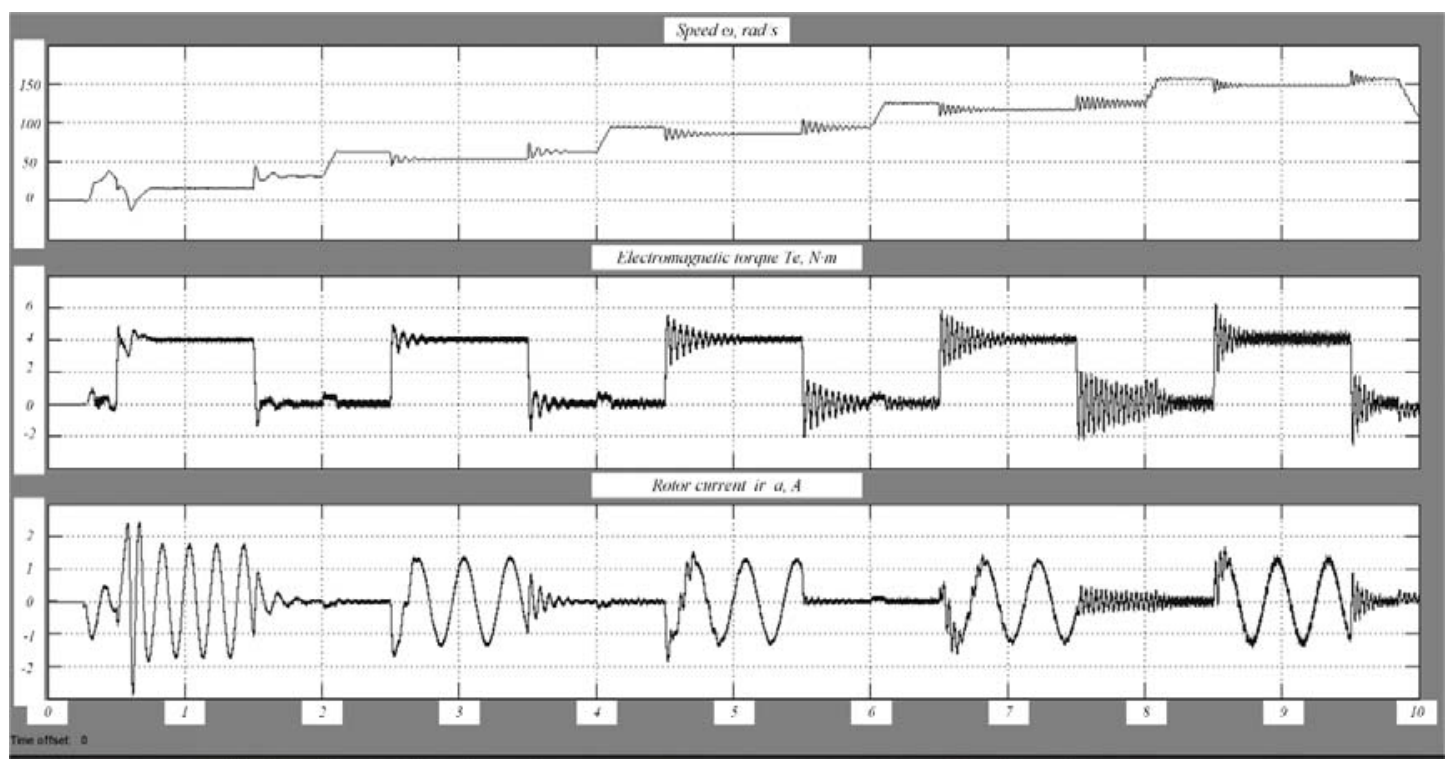

Figure 1. Modelling processes in an asynchronous electric drive with scalar control without feedback

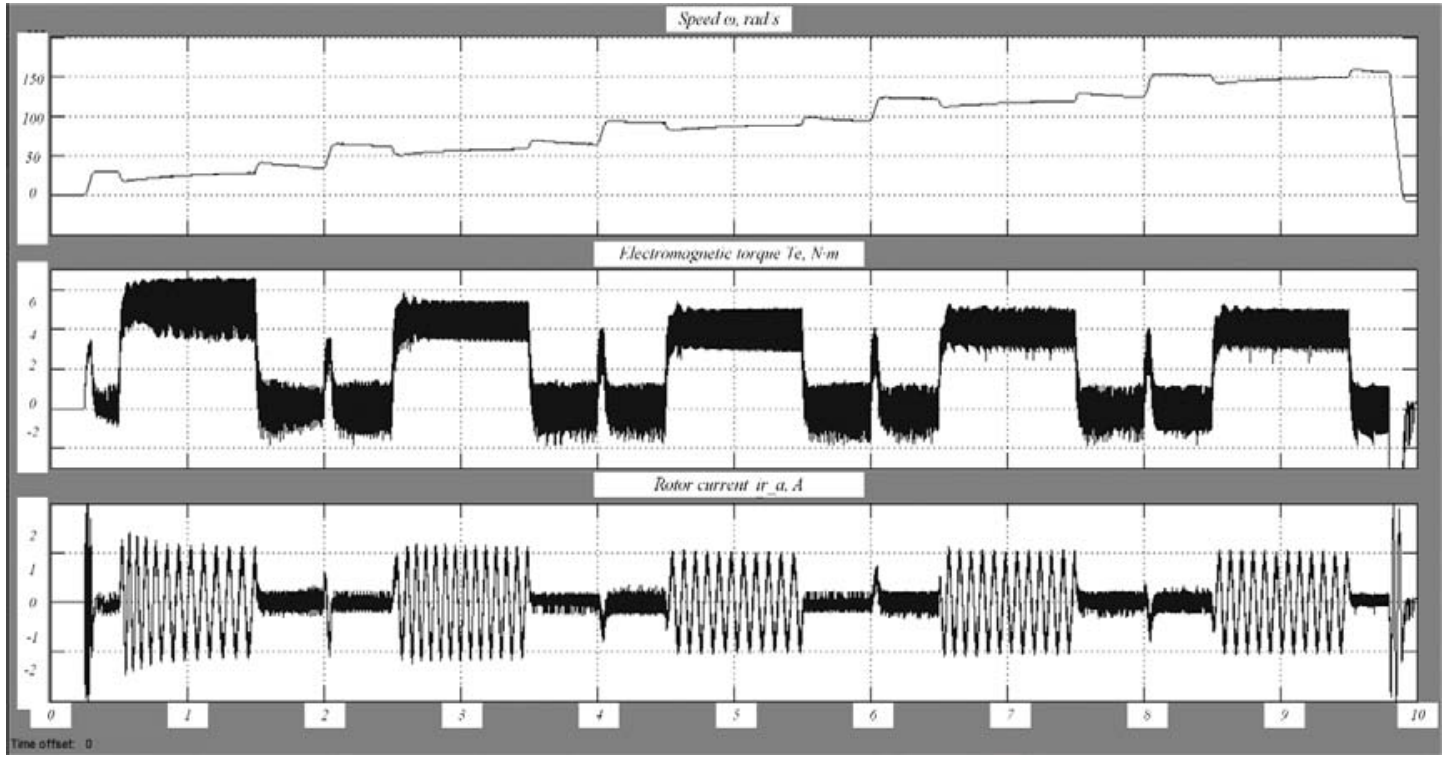

Figure 2. Modelling processes in an asynchronous electric drive with vector control system 


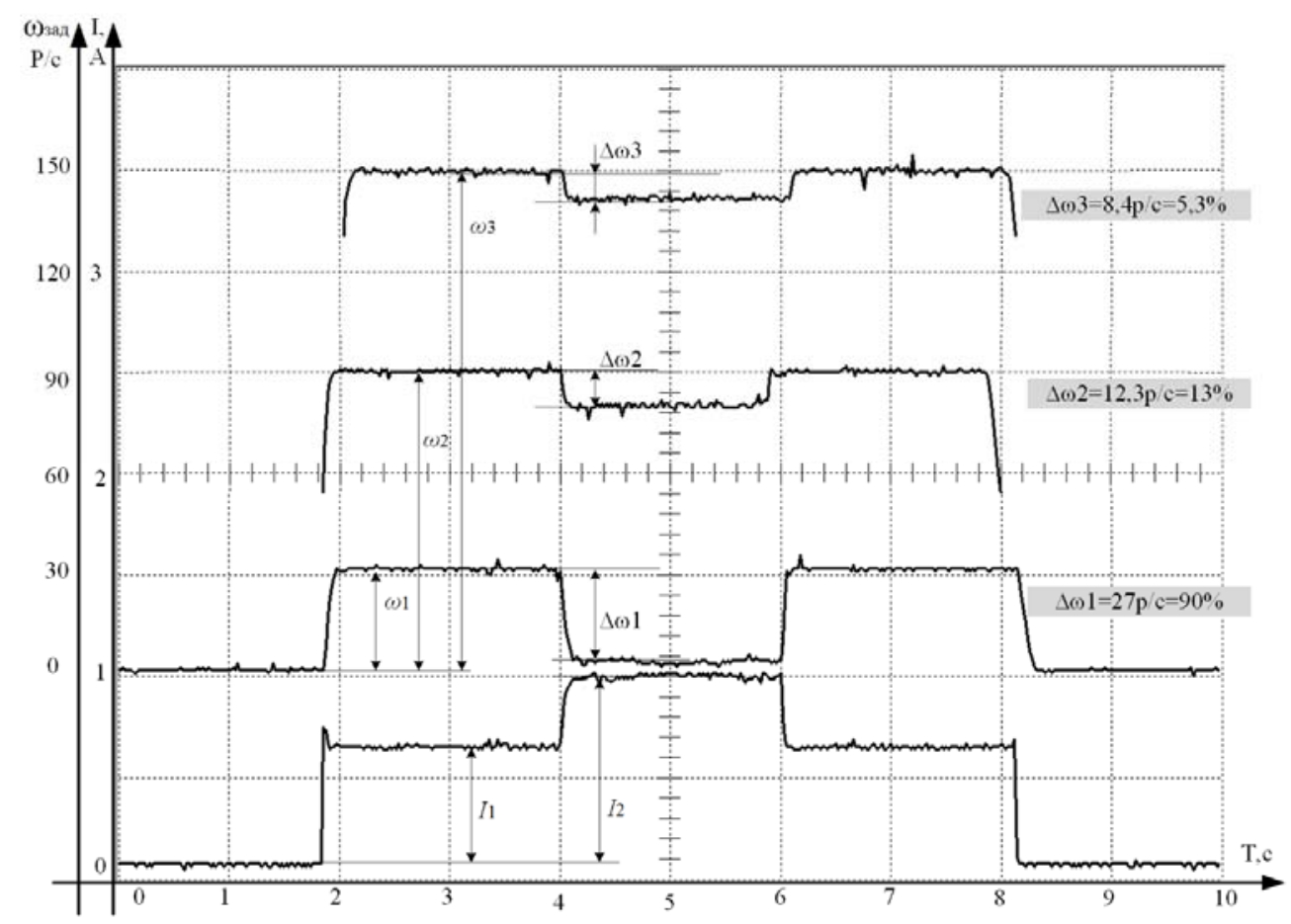

Figure 3. Experimental researches of the electric drive with the opened frequency control

\section{PROPOSED SOLUTION}

The basis for choosing the method for calculating the dynamic mechanical characteristic, proposed in the same monograph AA. Usoltseva [11, p.135].

$$
m=\frac{2 M_{k}}{\left(1+T_{2}^{\prime} p\right)\left[\frac{S_{k}}{\beta}\left(1+T_{2}^{\prime} p\right)\right]+\frac{\beta}{S_{k}}},
$$

where: $T_{2}^{\prime}=\frac{1}{S_{k^{\prime}} \omega_{1 \text { ном }}}-$ rotary time constant, $\beta=\frac{\omega_{2}}{\omega_{1 \text { ном }}}-$ absolute slip.

This formula Usoltsev A.A. calls a dynamic mechanical characteristic and simplifies it to a firstorder dynamic link that can not be described by the processes presented in Figures 1-3.

The refinement of the linearization conditions allows us to obtain a different formula for the dynamic link connecting the torque developed by the induction motor with the rotational speed (Kloss dynamic formula), while some of the coefficients of the formula depend on the frequency of the supply voltage and slip.

Since, the experiments necessary for testing the theoretical positions were carried out on a laboratory bench with electric motors AIR63V4U3 - all the frequency responses were calculated taking into account the technical parameters of this motors. Specific frequency responses for the frequencies of the supply voltage of $10,20,30,40$ and $50 \mathrm{~Hz}$ were calculated, as well as the slip of $3 \%, 8.6 \%$ and $17.2 \%$ is shown in Figures 4-7.

$$
m=\frac{2 M_{k}\left(T_{2}^{\prime} p+1\right)}{\left(1+T_{2} \prime p\right)^{2} \frac{S_{k}}{\beta}+\frac{\beta}{S_{k}}} .
$$

The dynamic mechanical characteristic for the frequencies of the supply voltage of $10 \mathrm{~Hz}$ has the form (3), and for $50 \mathrm{~Hz}$ it has the form (4), and the frequency responses for these frequencies for slides of $3 \%, 8.6 \%$ and $17.2 \%$ are shown in Figures 4 and 5 .

Int J Pow Elec \& Dri Syst, Vol. 10, No. 1, March 2019: $66-73$ 


$$
m=\frac{0,852 p+3,611}{(1+0,236 p)^{2} \frac{0,135}{\beta(S)}+\frac{\beta(S)}{0,135}}
$$

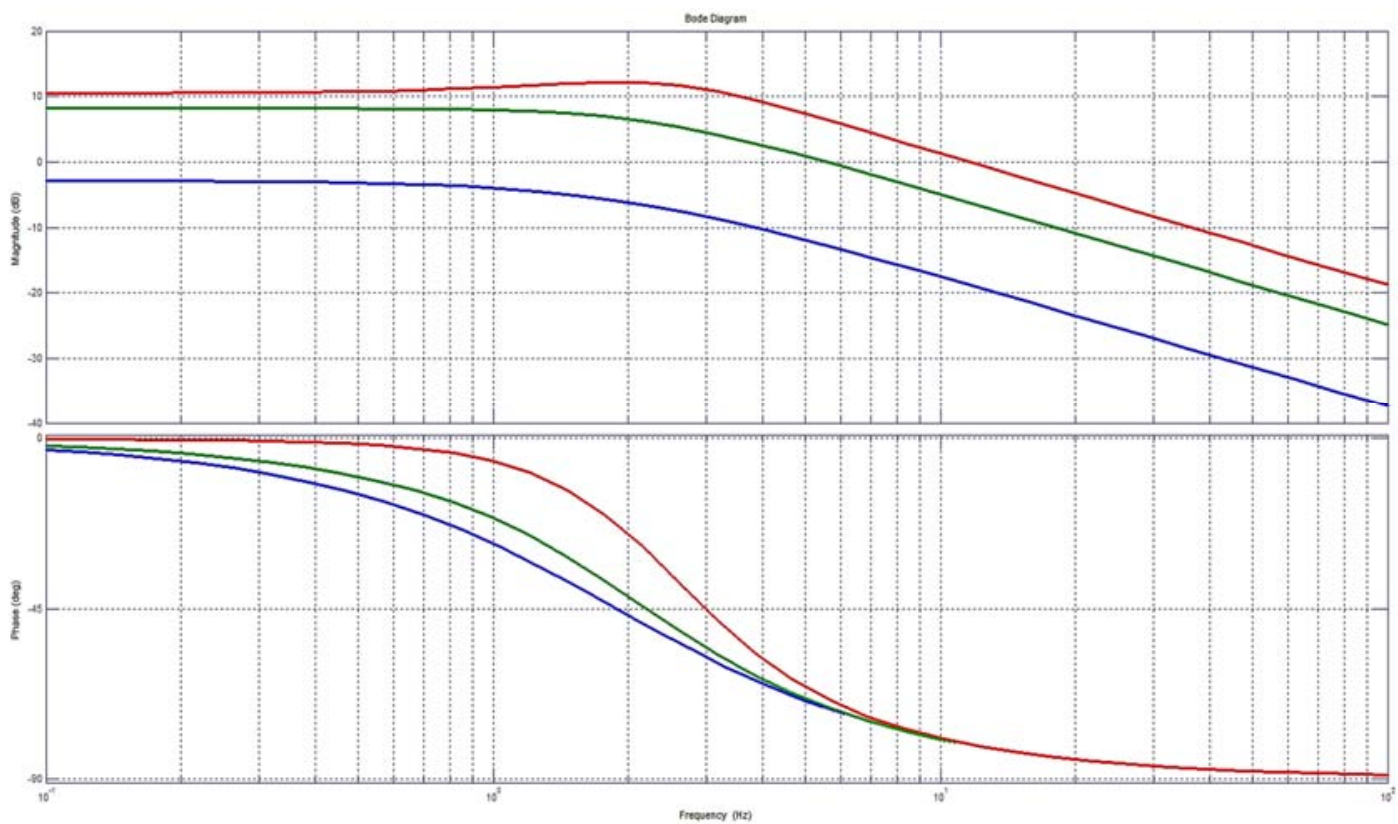

Figure 4. Frequency responses of the channel of formation of the moment for various slides (blue $-\beta 1=3 \%$, green $-\beta 2=8.6 \%$, red $-\beta 3=17.2 \%$, for $10 \mathrm{~Hz}$

$$
m=\frac{0,182 p+10,316}{(1+0,176 p)^{2} \frac{0,36}{\beta(S)}+\frac{\beta(S)}{0,36}}
$$

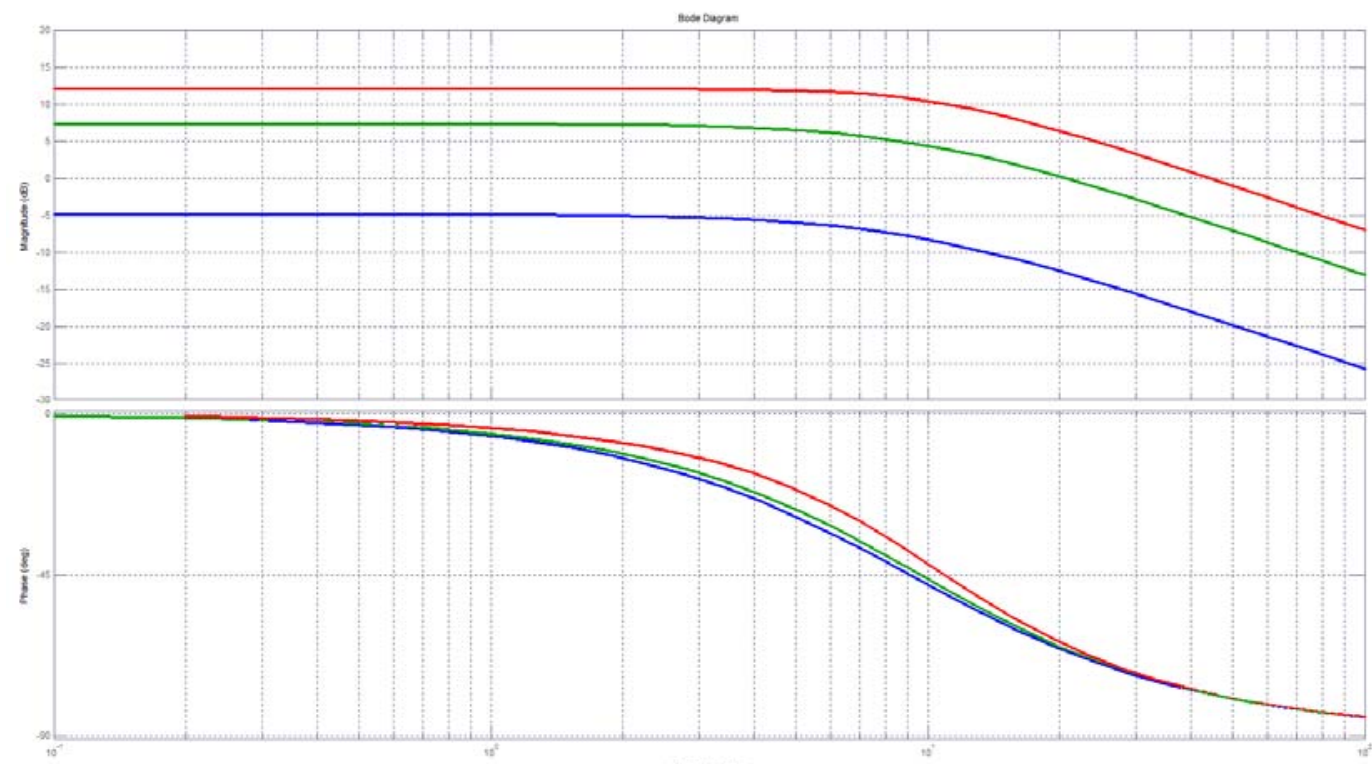

Imener ats

Figure 5. Frequency responses of the channel of formation of the moment for various slides (blue $-\beta 1=3 \%$, green $-\beta 2=8.6 \%$, red $-\beta 3=17.2 \%$ ) for $50 \mathrm{~Hz}$ 
The main changes in the phase characteristics fall on the frequency range from 1 to $10 \mathrm{~Hz}$. This is the range in which the cut-off frequencies of the majority of medium-power industrial drives (from 1 to 200 $\mathrm{kW}$ ) are located. To compensate for this phenomenon, it is necessary to reduce the variability of frequency responses. This is done by vector control. But unsuccessfully. This variability also does not change with negative connections and the acceleration of internal circuits. It can only be reduced by introducing terms in the denominator with negative coefficients, i.e. introducing a positive feedback. The most practical variant of such a connection may be an inverse positive coupling with respect to the stator current. Ensuring the stability of asynchronous electric drives with such a connection and the results of experimental studies of electric drives with it are considered in articles [20]. The families of frequency responses proposed in this article explain well its positive actions

The families of frequency responses obtained are grouped according to frequencies is shown in Figure 4 and slip is shown in Figure 5. The characteristics, grouped according to the slip values, show that during acceleration to nominal speed, the negative phase shift in the operating frequency range $(1-10 \mathrm{~Hz})$ changes by 50 degrees. This can significantly affect the stability and dynamics of overclocking processes. This influence is observed in simulation and experimental studies, accelerations up to $10 \mathrm{~Hz}$ with scalar control are accompanied by current and speed oscillations, while other dispersals are practically monotonic. The vector control problems arising from the mismatch of the control unit model parameters are also well explained by the transfer functions and frequency responses, if their parameters do not coincide, their serial connection forms a complex structure prone to oscillation.

The dynamic mechanical characteristic with a slip of $3 \%$ has the form (5), and at $8.6 \%$ has the form (6), and the frequency responses for these slides for the supply voltage frequencies 10,30 and $50 \mathrm{~Hz}$ are given in Figures 6 and 7.

$$
m=\frac{2 M_{k}(\omega)\left(T_{2}^{\prime}(\omega) p+1\right)}{\left(1+T_{2}{ }^{\prime}(\omega) p\right)^{2} \frac{S_{k}(\omega)}{0,03}+\frac{0,03}{S_{k}(\omega)}} .
$$
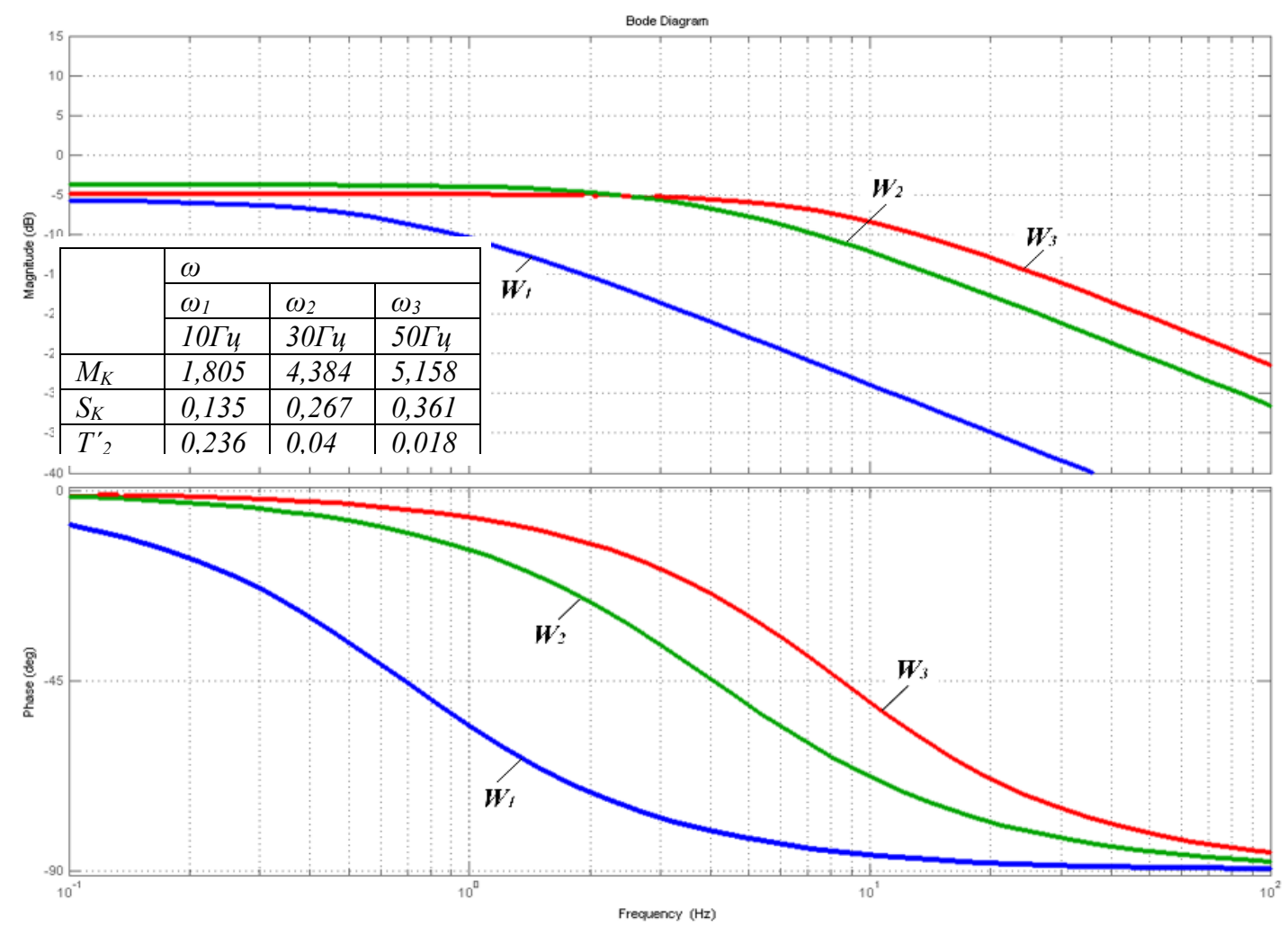

Figure 6. Frequency responses of the link for the formation of torque when sliding $3 \%$ for frequencies 10,30 and $50 \mathrm{~Hz}$ 


$$
m=\frac{2 M_{k}(\omega)\left(T_{2}^{\prime}(\omega) p+1\right)}{\left(1+T_{2}{ }^{\prime}(\omega) p\right)^{2} \frac{S_{k}(\omega)}{0,086}+\frac{0,086}{S_{k}(\omega)}} .
$$

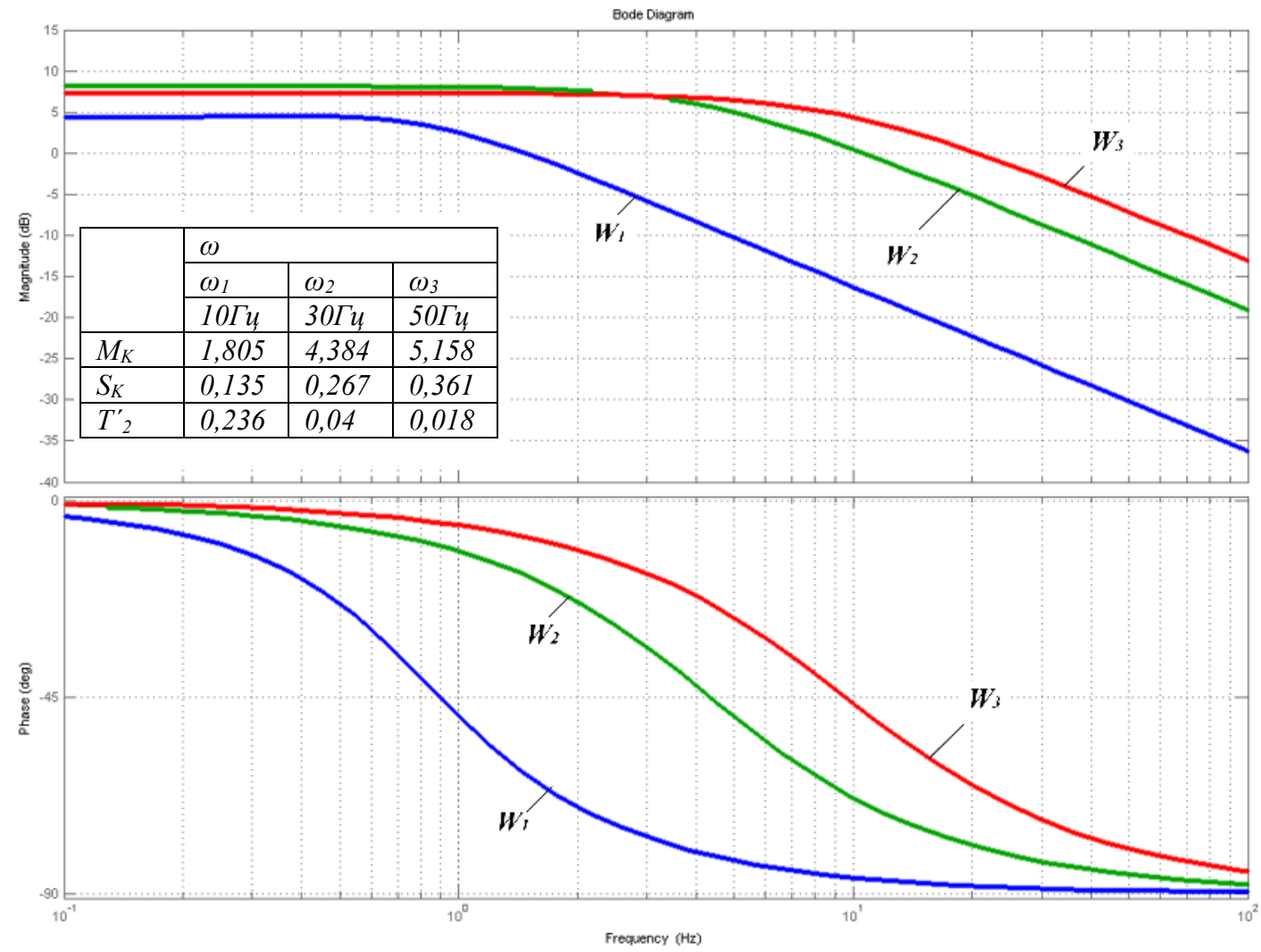

Figure 7. Frequency responses of the link for the formation of torque when sliding $8.6 \%$ for frequencies 10 , 30 and $50 \mathrm{~Hz}$

By family of frequency responses, grouped by the frequencies of the supply voltage for various slip is shown in Figures 6 and 7, we can evaluate the nature of the processes in the case of load skews at different rotational speeds. At $50 \mathrm{~Hz}$, the slip changes practically do not change the frequency response, whereas at 10 and $30 \mathrm{~Hz}$ the changes are significant. Therefore, the processes of parrying the load at these speeds look more complicated.

The calculated frequency responses can explain a number of results obtained earlier in the course of the experiments. Thus, control failures at various parameters of the sinusoidal reference signals (amplitudes and frequencies) described in [16], [21], [22] can be explained by the fact that the slip sk in the formula (2) can change the value, and then it is practically impossible to avoid the unstable characteristic, and to calculate these conditions pretty hard.

According to the formulas is shown in Figures 4-7, it is possible to explain the efficiency of the positive feedback on the current of the stator of the electric motor, described in the articles [14], [20], [23]. As seen from the formula (7), (-0,06p2 its coefficient obtained from positive feedback), positive feedback reduces the variability of the frequency responses of the speed of rotation and slip.

$$
m=\frac{0,182 p+10,316}{(1+0,0176 p)^{2} \frac{0,36}{\beta(S)}+\frac{\beta(S)}{0,36}-0,06 p^{2}}
$$

The formulas (7) for the frequency responses of a drive with a positive stator current feedback is shown in Figure 8 have a significantly lower frequency response from frequency $\mathrm{f}$ and slip $\mathrm{S}$, which explains the stability of transients during acceleration and load spikes at different rotational speeds. This also explains the considerably smaller differences in the processes at different rotational speeds. These frequency

The dynamics identification of asynchronous electric drives via frequency response (Vladimir L. Kodkin) 
responses are close to the frequency responses of DC drives, which opens up prospects for their use in complex mechanisms, including drives for industrial robots.

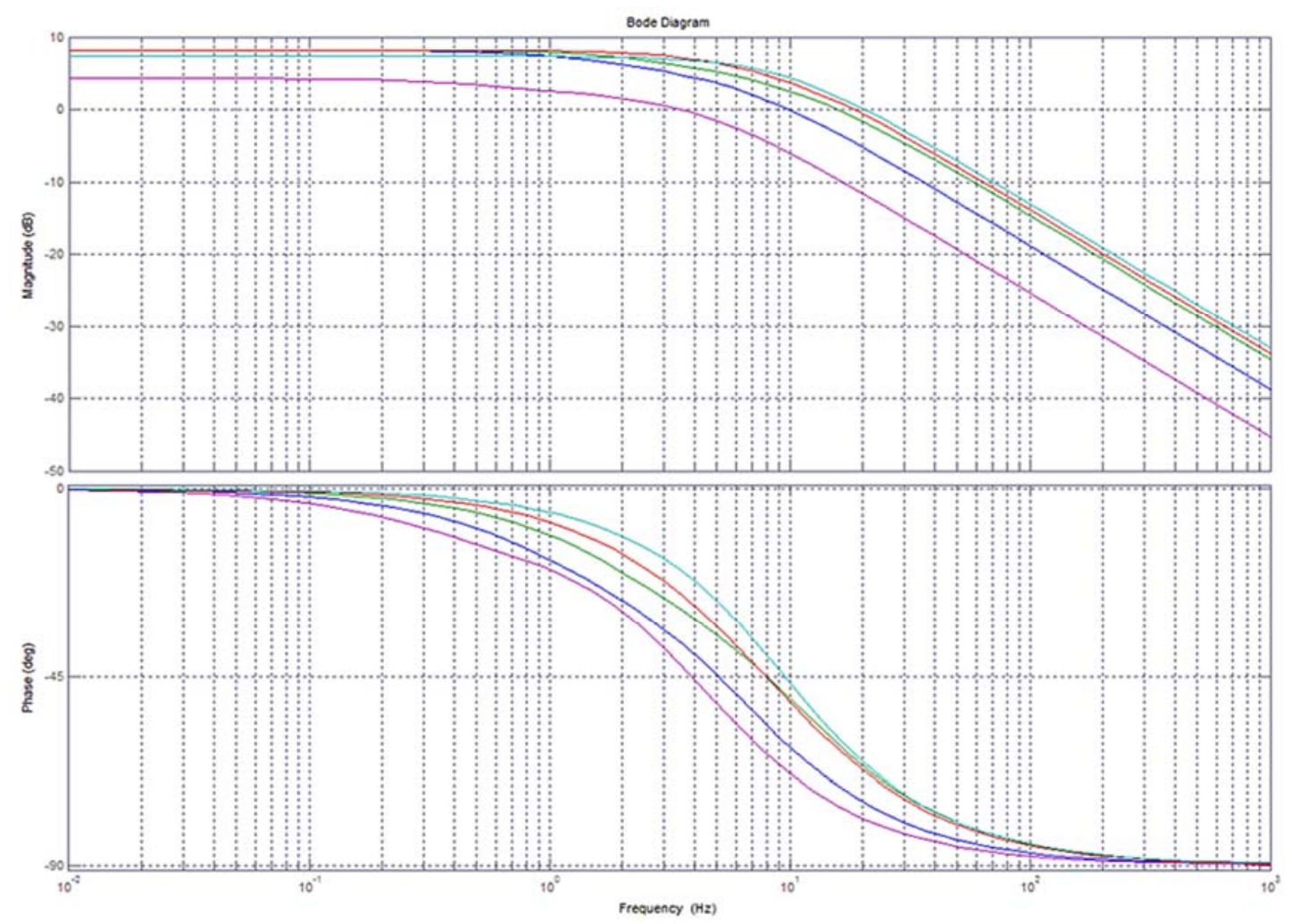

Figure 8. Frequency responses of an electric drive with a positive stator current feedback

\section{CONCLUSIONS}

The proposed method of identifying AC drives by families of frequency responses that depend on the frequency of supply voltage and slip, very effectively explain the nonlinear nature of the processes in the $\mathrm{AC}$ drive. The above identification method allows us to formulate the principles of correction of AC electric drives. The proposed correction - dynamic positive feedback on stator current - will allow the use of an AC drive (asynchronous drive) in technical complexes.

\section{REFERENCES}

[1] Cubero Sam (ed.) Industrial Robotics. Theory, Modelling and Control / Pro Literatur Verlag, p.952, 2007.

[2] Low K.-H. (ed.) Industrial Robotics. Programming, Simulation and Applications / InTech, p. 700, 2007.

[3] N. A. Sukhenko, G. Ya. Pyatibratov, A. A. Danshina, L. L, "Altunyan Prospective Electromechanical Control Systems of Industrial Manipulator Efforts," International Journal of Power Electronics and Drive System (IJPEDS), Vol. 7, No. 2, pp. 416 421, June 2016.

[4] Anikin A.S, "Dynamic positive coupling in asynchronous electric drives with frequency control / A.C. Anikin, V.L. Kodkin, A.A. Baldenkov," Priorities of world science: experiment and scientific discussion, Materials of the 8th international scientific conference. Scientific and Publishing Center "Otkrytie". North Charleston, SC, USA, 17-18, - P.119-124, June 2015.

[5] Kodkin V.L., Ya.A. Shmarin, A.S. Anikin, AA Baldenkov, N.A. Loginova, Correction of dynamic moment perturbations in electric drives of alternating current, Science of SUSU. Materials of the 68th scientific conference. P. 805-814, 2016.

[6] Li Yaohua, Ma Jian, Yu Qiang, Liu Jiangyu, "Novel Direct Torque Control Permanent Magnet Synchronous Motor Drive used in Electrical Vehicle," International Journal of Power Electronics and Drive System (IJPEDS), Vol.1, No.2, pp. 129 138, December 2011. 
[7] Kamel Saleh, "Mark Sumner Sensorless Control of a Fault Tolerant PMSM Drives in Case of Single-phase Open Circuit Fault," International Journal of Power Electronics and Drive System (IJPEDS), Vol. 7, No. 4, pp. 1061 1074, December 2016.

[8] Shevchenko, A.F. and Abdel' Maksud Selim, S.A., "Vector control of stator's current in synchronous motor with permanent magnets for drowned pump drive," Nauchn. Vestn. Novosib. Gos. Tekhn. Univ., 2011, no. 2(43)

[9] Louis J-P. Control of Non-conventional Synchronous Motors / Great Britain and the United States by ISTE Ltd and John Wiley \& Sons, Inc., 428 p., 2012.

[10] Rik De Doncker, Duco W.J. Pulle, Andre Veltman, “Advanced Electrical Drives: Analysis, Modeling, Control. Springer," 474 p., 2011

[11] Usoltsev, A.A. Vector control of asynchronous motors. Tutorial. - Spb .: ITMO, 120 p., 2002. http://servomotors.ru/documentation/frequency_control_of_asynchronous_motors/chastupr.pdf

[12] Pozdeev, A.D., "Electromagnetic and electromechanical processes in frequency-controlled asynchronous electric drives," - Cheboksary: Publishing house Chuvash University, 172 p., 1998.

[13] Sokolovsky, G.G. AC electric drives with frequency control. - Moscow: "ACADEMIA", 267 p., 2006.

[14] Kodkin V.L., "Experimental Research of Asynchronous Electric Drive with Positive Dynamic Feedback on Stator Current," III International Conference on Industrial Engineering, Applications and Manufacturing, ICIEAM 2017 - Proceedings. - 2017

[15] V.L. Kodkin, A.S. Anikin, Ya.A. Shmarin, "Dynamic Load Disturbance Correction for Alternative Current Electric Drives" II International Conference on Industrial Engineering, Applications and Manufacturing, ICIEAM $2016-$ Proceedings. - 2017

[16] Kodkin V. L., Anikin A. S., "Frequency control of asynchronous electric drives in transport," 2015 International Siberian Conference on Control and Communications (SIBCON), 2015.

[17] V.L. Kodkin, A.S. Anikin, Ya.A., "Shmarin Effective Frequency Control for Induction Electric Drives under Overloading Russian Electrical Engineering," Vol. 85, No. 10, pp. 641-644, 2014.

[18] Park R., Robertson B. The reactances of synchronous machines. // Tr. AIEE,vol. 47, 1928.

[19] Chiasson John. Modeling And High Performance Control Of Electric Machines / John Wiley \& Sons, Inc., 709 p, 2005.

[20] V.L. Kodkin, A.S. Anikin, A.A. Baldenkov, "Analysis of stability of electric drives as non-linear systems according to Popov criterion adjusted to amplitude and phase frequency characteristics of its elements" 2nd International Conference on Applied Mathematics, Simulation, and Modeling AMSM 2017 - Proceedings. - 2017.

[21] V.L. Kodkin, A.S. Anikin, A.A. Baldenkov, "Spectral Analysis of Rotor Currents in Frequency-controlled Electric Drives" 2nd International Conference on Automation, Mechanical and Electrical Engineering, AMEE 2017 Proceedings. - 2017

[22] V.L. Kodkin, A.S. Anikin, A.A. Baldenkov, "The analysis of the quality of the frequency control of induction motor carried out on the basis of the processes in the rotor circuit" XI International Scientific and Technical Conference "Dynamics of Systems, Mechanisms and Machines, Proceedings, 2017.Omsk, 14-16.11.2017.

[23] Kodkin. V.L., "Methods of optimizing the speed and accuracy of optical complex guidance systems based on equivalence of automatic control system domain of attraction and unconditional stability of their equivalent circuits," Proceedings of SPIE - The International Society for Optical Engineering. - 2016. 